\title{
Fetal cord blood and tissue immune responses to chronic placental inflammation and chorioamnionitis
}

\author{
Anne Marie Singh ${ }^{1,6 \dagger}$, Michael G. Sherenian ${ }^{1 \dagger}$, Kwang-Youn Kim², Kristin A. Erickson ${ }^{6}$, Amy Yang ${ }^{3}$, \\ Karen Mestan ${ }^{4}$, Linda M. Ernst ${ }^{5}$ and Rajesh Kumar ${ }^{\text {* }}$
}

\begin{abstract}
Background: Chorioamnionitis is a risk factor for future asthma development. Animal models of chorioamnionitis demonstrate increased $T_{H}$ 17-to- $T_{\text {reg }}$ ratios associated with proinflammatory cytokine elevations. The association of chorioamnionitis on human neonatal immune cells systemically and within tissues is not known.

Methods: We enrolled two cohorts to evaluate $T_{H} 17$ and regulatory $T$ cell $\left(T_{\text {reg }}\right)$ phenotypic markers in chorioamnionitis. From a cohort of 19 live birth infants, we collected cord blood and placenta samples to evaluate for signs of acute and chronic histologic inflammation and cell phenotype characterization. We analyzed a second cohort of stillborn infants with and without chorioamnionitis to classify and enumerate cell infiltrate phenotypes in the spleen, thymus, and lung. We used linear regression analysis determine the association of retinoic acid-related orphan receptor gamma t positive $\left(\mathrm{RORyt}^{+}\right)$and $\mathrm{T}_{\text {reg }}$ cell frequency with different types of inflammation seen in the live cohort subjects. Using linear mixed models, we evaluated for any associations between chorioamnionitis and Tand B-cell with a logarithmic scale for level of expression of cellular markers. We then performed Wilcoxon rank sum tests to assess the associations between cell count and chorioamnionitis.
\end{abstract}

Results: In the live birth subjects with chronic placental inflammation we observed an increased proportion of $\mathrm{RORYt}^{+}$cells in Foxp $3^{+}$cells, regardless of the presence of acute inflammation, compared to subjects with neither acute nor chronic inflammation. We also found an increased proportion of RORyt ${ }^{+}$cells within Foxp3 ${ }^{+}$cells in $^{2}$ subjects with acute high stage fetal and maternal inflammation compared to those without acute or chronic inflammation. In the stillborn subjects with chorioamnionitis, we observed a decrease in splenic Foxp $3^{+}$cells and an increase in lung $\mathrm{CD}^{+}$cells compared with subjects that did not have chorioamnionitis.

Conclusion: Exposure to chorioamnionitis in utero may affect immune activation in neonates with an increased frequency of RORyt ${ }^{+}$cells systemically as well as lymphocytic infiltrate in the lung. Our findings suggest an increase in $\mathrm{RORYt}^{+}$cells during chorioamnionitis and thus may support the known associations between chorioamnionitis with asthma.

Keywords: Chorioamnionitis, Asthma, Pediatrics, T cells, Foxp3, RORyt

\footnotetext{
${ }^{*}$ Correspondence: rkumar@luriechildrens.org

${ }^{\dagger}$ Anne Marie Singh and Michael G. Sherenian contributed equally to this

work

${ }^{1}$ Division of Allergy and Immunology, Department of Pediatrics,

Northwestern Feinberg School of Medicine, Ann and Robert H. Lurie

Children's Hospital of Chicago, 255 E Chicago Ave, Box \#60, Chicago, IL

60611 , USA

Full list of author information is available at the end of the article
}

(c) The Author(s) 2018. This article is distributed under the terms of the Creative Commons Attribution 4.0 International License (http://creativecommons.org/licenses/by/4.0/), which permits unrestricted use, distribution, and reproduction in any medium, provided you give appropriate credit to the original author(s) and the source, provide a link to the Creative Commons license, and indicate if changes were made. The Creative Commons Public Domain Dedication waiver (http://creativecommons.org/ publicdomain/zero/1.0/) applies to the data made available in this article, unless otherwise stated. 


\section{Background}

Factors affecting lung growth or lung function in fetal life may have a long-term effect on lung disease later in life [1, 2]. Histologic chorioamnionitis, a common inflammation of the maternal-fetal interface, complicates $8 \%$ of pregnancies, and is present in more than $50 \%$ of preterm births [3]. Previously, we, and others, demonstrated an association between chorioamnionitis and wheezing/ asthma, decreased lung function, and other respiratory morbidities [1, 2, 4-8]. However, the mechanisms by which chorioamnionitis leads to wheezing, asthma or altered lung function are not well understood.

Chorioamnionitis may promote an inflammatory state in neonate [9]. Indeed, it has been shown that cord blood levels of interleukin (IL) $1 \beta$ and IL- 6 increase in neonates with chorioamnionitis. IL-6 exposure may then alter T-cell development to promote development of T-helper-cell $17\left(\mathrm{~T}_{\mathrm{H}} 17\right)$ effector responses and may also repress regulatory $\mathrm{T}$-cell $\left(\mathrm{T}_{\text {reg }}\right)$ development. The "master regulator" of Th17 cells is retinoic acid-related orphan receptor gamma (ROR $\gamma \mathrm{t})$, which directs the development of Th17 cells [10]. These cells have been found to mediate inflammation, autoimmune disease, and may also protect from extracellular pathogens [11]. Regulatory $\mathrm{T}$ cells are diverse set of $\mathrm{T}$ cells that maintain immune homeostasis, tolerance and limit inflammation. FOXP3 has been identified as the master regulator of Treg development $[12,13]$. It is suspected that $T_{\text {reg }}$ and $T_{H} 17$ cells may be reciprocally regulated, and IL-17+ like Tregs have been described. These IL-17+ $\mathrm{T}_{\text {reg }}$ cells differentiate to inflammatory $\mathrm{T}_{\mathrm{H}} 17$ ex vivo, with a loss of FOXP3 expression [14]. Further complicating the issue, these cells have also been found to be immunosuppressive in the gut, likely promoting tolerance to extracellular microbes $[15,16]$. Thus, the changes in cytokine expression in neonates with chorioamnionitis may eventually promote immune dysregulation, airway remodeling via mucous cell metaplasia, smooth muscle proliferation/migration, and further $\mathrm{T}_{\mathrm{H}} 17$ activation. Furthermore, animal models of chorioamnionitis demonstrate an increased lung and splenic $\mathrm{T}_{\mathrm{H}}$ 17-to$\mathrm{T}_{\text {reg }}$ ratio, which establishes a proinflammatory state [17-19]. However, the effects of chorioamnionitis on human fetal immune deviation and T-cell subsets have not been established. We hypothesized that, in human fetuses, chorioamnionitis is associated with systemic differences in regulatory $\mathrm{T}$ cells and $\mathrm{T}_{\mathrm{H}} 17$ cell number. We also hypothesized that there would be tissue specific differences in regulatory $\mathrm{T}$ cell profiles in the tissues. To evaluate these hypotheses, we examined two cohorts. We first prospectively investigated cord blood from 19 infants with clinical chorioamnionitis for T-cell marker expression. Second, we sought to determine any tissue specific alterations by evaluating a retrospective cohort of 20 still births of varying gestational age with and without chorioamnionitis.

\section{Methods \\ Live birth cohort}

Nineteen live preterm neonates delivered between 28 and 35 gestational weeks were enrolled. We obtained cord blood and placental samples from all enrolled infants under an institutional review board approved protocol. We performed hematoxylin and eosin (H\&E) staining on all placental samples to assess for the presence of acute and chronic inflammation. We defined acute histologic chorioamnionitis as the presence of any marginating neutrophils in the extraplacental membranes, chorionic plate or umbilical cord. We then divided inflammation into maternal and/or fetal acute inflammatory responses. We assessed and staged the maternal acute inflammatory response in the membranes and chorionic plate as follows: Stage 1 for acute subchorionitis and chorionitis; Stage 2 for acute chorioamnionitis; Stage 3 for necrotizing acute chorioamnionitis. We considered Stage 2 or 3 maternal acute inflammation as high staging. We then classified maternal high stage subjects as having maternal evidence of acute chorioamnionitis for our analysis. We assessed and staged fetal acute inflammatory response in the chorionic plate vessels or umbilical cord as follows: Stage 1 for acute umbilical phlebitis or acute chorionic vasculitis; Stage 2 for acute umbilical arteritis, Stage 3 for acute necrotizing funisitis. We considered Stage 2 or 3 fetal acute inflammation as high stage. We then classified fetal high stage subjects on the presence of evidence for fetal acute chorioamnionitis for our analysis.

We also delineated the presence of chronic placental inflammation, which was characterized when we observed chronic inflammatory cells (lymphocytes, histiocytes, or plasma cells) in the membranes (chronic chorioamnionitis, chronic choriodeciduitis), basal plate (chronic deciduitis with plasma cells, chronic decidual perivasculitis), or villi (low or high grade chronic villitis, chronic intervillositis).

We recruited 12 preterm neonates with histologic chorioamnionitis and seven gestational age-matched controls without clinical chorioamnionitis. We present the characteristics of the recruited subjects, stratified by the presence of clinical chorioamnionitis, in Table 1 . For the purposes of the analyses, we used histologic (not clinical) criteria to classify subjects. Of the 19 subjects, seven placentas had no histologic evidence of acute or chronic inflammation. Of the remaining 12 subjects, two subjects had maternal and fetal high stage acute inflammation in addition to chronic inflammation, one subject had maternal high stage acute inflammation 
Table 1 Demographic data for subjects that underwent cellular, cord blood, analyses

\begin{tabular}{|c|c|c|}
\hline & Chorioamnionitis $(n=12)$ & Control $(n=7)$ \\
\hline \multicolumn{3}{|l|}{ Maternal age (years) } \\
\hline Mean (range) & $33(18-47)$ & $29(20-37)$ \\
\hline Median (interquartile range) & $31(27-41)$ & $29(28-31)$ \\
\hline \multicolumn{3}{|l|}{ Maternal race } \\
\hline White & 4 & 1 \\
\hline Black & 6 & 6 \\
\hline Other & 2 & 0 \\
\hline \multicolumn{3}{|l|}{ Maternal ethnicity } \\
\hline Hispanic & 2 & 0 \\
\hline Non-Hispanic & 9 & 7 \\
\hline Declined & 1 & 0 \\
\hline Infant sex (male) & 6 & 3 \\
\hline \multicolumn{3}{|l|}{ Gestational age (weeks) } \\
\hline Mean (range) & $31(25-33)$ & $32(29-35)$ \\
\hline Median (interquartile Range) & $32(31-33)$ & $33(32-34)$ \\
\hline Preterm labor (yes) & 9 & 5 \\
\hline Premature rupture of membranes (yes) & 7 & 3 \\
\hline \multicolumn{3}{|l|}{ Membrane rupture } \\
\hline Artificial & 3 & 3 \\
\hline Spontaneous & 9 & 4 \\
\hline \multicolumn{3}{|l|}{ Mode of delivery } \\
\hline Vaginal & 8 & 5 \\
\hline Cesarean & 4 & 2 \\
\hline Multiple gestation (yes) & 5 & 3 \\
\hline Antenatal steroids (yes) & 6 & 4 \\
\hline Apgar at 1 min (average, range) & $5(1-9)$ & $7(3-9)$ \\
\hline Apgar at 5 min (average, range) & $8(7-9)$ & $8(8-9)$ \\
\hline \multicolumn{3}{|l|}{ Birthweight (grams) } \\
\hline Mean (range) & $1821(740-2525)$ & $1939(1220-2670)$ \\
\hline Median (interquartile range) & $1882(1734-1996)$ & $1855(1625-2290)$ \\
\hline
\end{tabular}

as well as chronic inflammation, one subject had maternal high stage acute inflammation but no chronic inflammation, and eight subjects had only chronic inflammation (Additional file 1: Figure S1).

To determine cord blood responses, we prospectively evaluated the T-cell phenotypes of the neonate via flow cytometry of cord blood from live preterm infants with and without chorioamnionitis. We evaluated cord blood mononuclear cells from the 19 neonates for surface and intracellular markers of $\mathrm{T}_{\text {reg }}$ and $\mathrm{T}_{\mathrm{H}} 17$ cells. We collected approximately $0.5-1 \mathrm{~mL}$ of cord blood from study participants in K2 EDTA tubes. We processed almost all samples immediately upon arrival, one patient was processed at approximately $24 \mathrm{~h}$. (Thus, all samples were processed within $30 \mathrm{~h}$ of collection.) For cord blood cell isolation, we used Ficoll gradient separation, washed the cells with PBS (sterile Dulbeccos' Phosphate buffered saline) and standard T-cell media, counted the cells and placed into flow tubes at $1 \times 10^{6}$ cells $/ 100 \mu \mathrm{L}$. We used the remaining cells for Fluorescence Minus One (FMO) controls. We then immediately stained the cells for flow cytometry analysis. We stained the cells for surface markers using the following antibody markers from the indicated source: CD3 APC-CY7 (SK7)Biolegend, CD4V-500 (RPA-T4) BD, CD25 APC (BC96)Biolegend, CD127 Pacific Blue (A019D5)-Biolegend. We then washed, fixed, and permeabilized the cells for intracellular staining with Forkhead Box P3 (Foxp3) Alexa Fluor 488 (206D)-Biolegend and retinoic acidrelated orphan receptor gamma t (ROR $\gamma \mathrm{t}$ ) PE (AKFJS-9) eBioscience. We performed acquisition using an LSR-II (BD, San Jose, CA) and analyzed using FlowJo software (Treestar, San Carlos, CA). We present the gating strategies for our flow analysis in Fig. 1. 


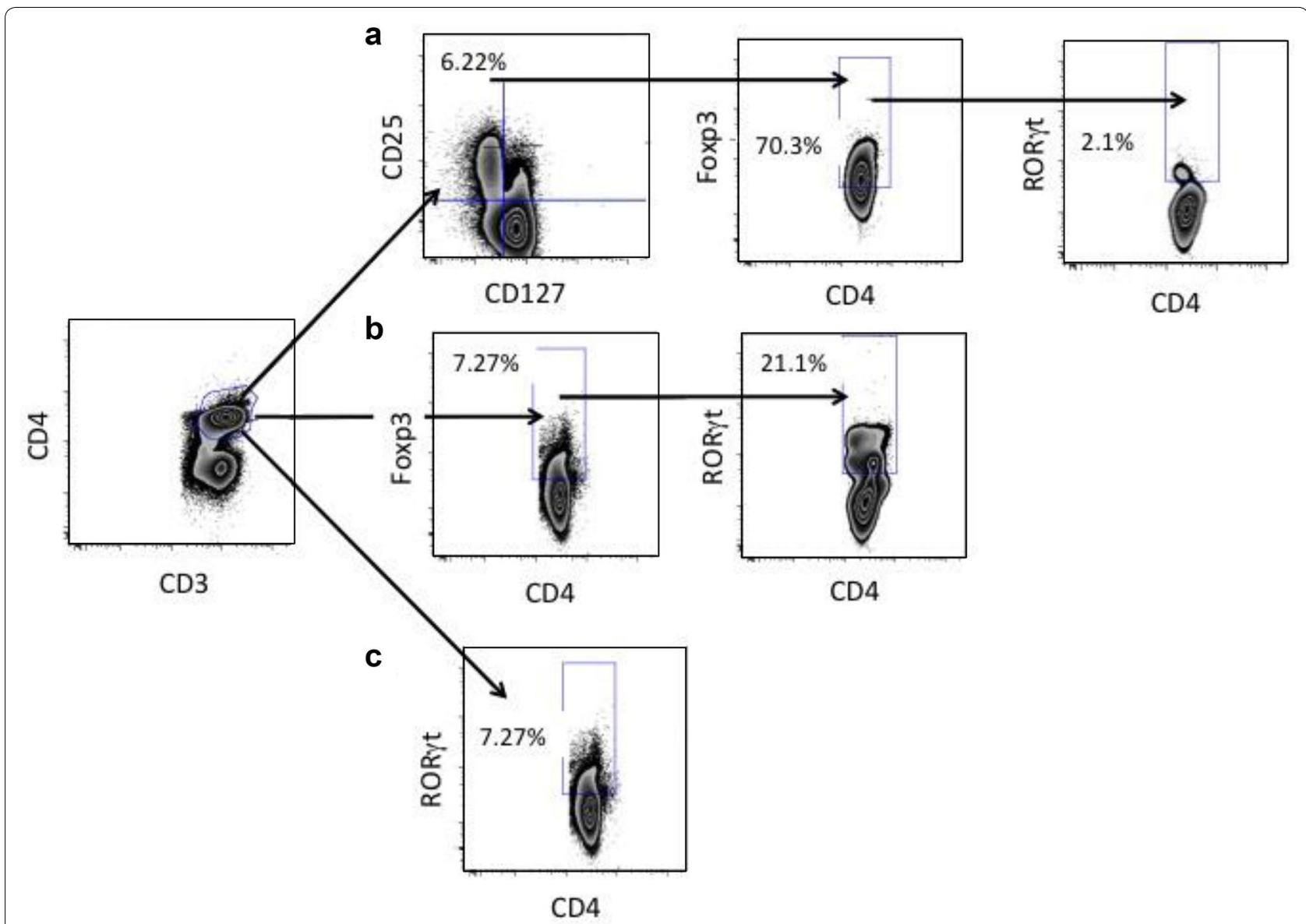

Fig. 1 Flow cytometry gating strategy for cord blood analysis and percentage of each population selected. For full details refer to "Methods" section within the text. a $\mathrm{CD} 25^{+} \mathrm{CD} 127^{-}$cells were gated from $\mathrm{CD}^{+} \mathrm{CD}^{+}$cells. Foxp3 ${ }^{+} \mathrm{CD} 4^{+}$cells were then gated from the $\mathrm{CD} 25^{+} \mathrm{CD} 127^{-}$cells. Lastly RORyt ${ }^{+} \mathrm{CD} 4^{+}$cells were selected from the Foxp $3^{+} \mathrm{CD} 4^{+}$cell population. $\mathbf{b}$ Foxp $3^{+} \mathrm{CD} 4^{+}$cells were selected from the initial $\mathrm{CD} 3^{+} \mathrm{CD} 4^{+}$population. These were then gated to select RORyt ${ }^{+} \mathrm{CD} 4^{+}$cells. $\mathbf{c}$ The initial $\mathrm{CD} 3^{+} \mathrm{CD} 4^{+}$cell population was gated to select $\mathrm{RORyt}^{+} \mathrm{CD} 4^{+}$cells

We defined regulatory T-cells as $\mathrm{CD}^{+}{ }^{+} \mathrm{CD} 4{ }^{+} \mathrm{CD} 25^{+} \mathrm{CD} 127^{\text {lo }}$ Foxp3 ${ }^{+}$cells within the lymphocyte gate. We examined expression of RORyt within $\mathrm{CD}^{+}{ }^{+} \mathrm{CD} 4^{+}$T-cells, $\mathrm{CD}^{+}{ }^{+} \mathrm{CD} 4^{+} \mathrm{Foxp}^{+}$cells and $\mathrm{CD}^{+} \mathrm{CD} 4{ }^{+} \mathrm{CD} 25^{+} \mathrm{CD} 127^{\text {lo }}$ Foxp $3^{+}$cells. We express cell data as the median percentage of cells within either the gated population of $\mathrm{CD}^{+}{ }^{+} \mathrm{CD} 4^{+} \mathrm{T}$-cells or the gated population of $\mathrm{CD}^{+} \mathrm{CD} 4{ }^{+} \mathrm{CD} 25^{\text {hi }} \mathrm{CD} 127^{\text {lo }}$ Foxp $3^{+} \mathrm{T}_{\text {reg }}$ cells for all fresh cord blood experiments.

\section{Stillbirth cohort}

To determine any tissue specific alterations, we identified thymic, splenic, and lung tissue samples derived from stillbirths of varying gestational ages, with and without chorioamnionitis. The purpose of this cohort was to identify any tissue specific alterations in immune cell phenotype in chorioamnionitis.

We previously collected these samples as per hospital procedure, along with family consent for their use in research. We excluded samples from multiple gestations with umbilical cords that could not be designated, demises secondary to a primary immunodeficiency, subjects with known congenital/cytogenetic abnormality, and subjects without available lung or placental tissue. We identified 10 cases with and 10 cases without chorioamnionitis. One exposed subject did not have adequate splenic tissue present on autopsy; two control subjects did not have adequate thymic tissue. We present demographic data for this group in Table 2.

We stained thymus, spleen, and lung samples by immunohistochemistry for CD3 (DAKO/A0452), CD20 (DAKO/M0755) and Foxp3 (ABCAM/AB20034). We used cellSens $^{\circledR}$ (Lombard, IL, USA) image analysis software and assessed 10 digital image fields of each tissue for each case. The results were expressed as a mean percentage of the field occupied by the positive staining. We did not complete RORyt quantification because of technical problems with the staining. 
Table 2 Demographics pertaining to subjects that underwent tissue specific analyses

\begin{tabular}{lll}
\hline & $\begin{array}{l}\text { Chorioamnionitis } \\
(\mathbf{n = 1 0})\end{array}$ & Control $\mathbf{n}=\mathbf{1 0})$ \\
\hline $\begin{array}{ll}\text { Maternal age (years) } \\
\text { Average (range) }\end{array}$ & $31(23-40)$ & $30(21-38)$ \\
Median (interquartile range) & $23(21-24)$ & $31(26-35)$ \\
Race & & \\
White & 5 & 3 \\
Black & 5 & 3 \\
Hispanic & 0 & 2 \\
Asian & 0 & 1 \\
Other & 0 & 1 \\
Sex & & 4 \\
Male & 5 & $23.8(19-34)$ \\
Gestational age & & $22(20.3-23.8)$ \\
Mean (range) & $25.4(18-40)$ & \\
Median (interquartile range) & $23(21.3-24)$ & \\
\hline
\end{tabular}

\section{Statistical analyses \\ Cord blood analyses}

We performed linear regression analysis to determine the association of $\mathrm{ROR}^{+} \mathrm{t}^{+}$expression in the Foxp3 ${ }^{+}$cells $\left(\mathrm{CD}^{+} \mathrm{CD}^{+}{ }^{+} \mathrm{Foxp}^{+}\right)$and $\mathrm{T}_{\text {reg }}$ cells $\left(\mathrm{CD} 3^{+} \mathrm{CD} 4^{+} \mathrm{CD} 25^{+} \mathrm{CD} 127^{\text {lo }} \mathrm{Foxp}^{+}\right)$in individuals with chronic inflammation only (no fetal acute chorioamnionitis) compared to controls without acute high stage or chronic inflammation. We carried out similar regressions evaluating $\mathrm{ROR}^{+} \mathrm{t}^{+}$expression in the Foxp $3^{+}$cells $\left(\mathrm{CD}^{+} \mathrm{CD}^{+} \mathrm{Foxp}^{+}\right)$and T-regulatory cells $\left(\mathrm{CD} 3^{+} \mathrm{CD} 4^{+} \mathrm{CD} 25^{+} \mathrm{CD} 127^{\text {lo }} \mathrm{Foxp} 3^{+}\right)$in individuals with maternal inflammation only compared to subjects without acute high stage or chronic inflammation. We repeated this analysis comparing subjects with fetal inflammation to subjects without acute high stage or chronic inflammation. Given the low numbers, we presented the unadjusted results to avoid over-adjustment.

\section{Tissue analyses}

To account for correlations due to repeated measures, we performed a linear mixed model analysis to evaluate for any associations between chorioamnionitis and CD20, CD3, and Foxp3 expression. Due to skewness of all markers, we used a logarithmic scale for level of expression of CD20, CD3, and Foxp3 in our analysis. We used a secondary non-parametric analysis to account for the data non-normality. Due to variation in tissue composition and expected lymphoid cell density, we ranked the samples by cell number and retained the five images with the largest areas stained to be used as representative of the whole. We then used the median percent area stained of those images from the subjects to perform the nonparametric Wilcoxon rank sum tests.

We used STATA SE version 11 (College Station, TX, USA) to perform all analyses. The institutional review boards of the Ann and Robert H. Lurie Children's Hospital of Chicago, and Northwestern University Feinberg School of Medicine approved the study.

\section{Results \\ Live birth cohort}

We found a significantly increased proportion of RORyt ${ }^{+}$ cells within the Foxp $3^{+}$cells $\left(\mathrm{CD}^{+}{ }^{+} \mathrm{CD} 4^{+} \mathrm{Foxp}^{+}{ }^{+} \mathrm{ROR} \gamma \mathrm{t}^{+}\right)$ among individuals with chronic inflammation (no high stage acute inflammation) ( $\beta \pm$ SE: $14.19 \pm 3.59, p=0.002$; Table 3) when compared to individuals with neither acute or chronic inflammation. A sensitivity analysis in all individuals with chronic inflammation (regardless of the presence of acute inflammation, $\mathrm{n}=19$ ) also revealed significantly increased proportions of $\mathrm{ROR}^{+} \mathrm{t}^{+}$in the Foxp $3^{+}$cells $\left(\mathrm{CD}^{+}{ }^{+} \mathrm{CD} 4^{+} \mathrm{Foxp}^{+}{ }^{\mathrm{ROR} \gamma \mathrm{t}^{+}}\right)$compared to those with no acute or chronic inflammation ( $\beta \pm$ SE: $14.18 \pm 3.59, \quad p=0.002)$. Interestingly, we found no statistically significant difference $(\beta:-1.09$, $\mathrm{SE}: 2.04, p=0.54$; Table 3 ) in $\mathrm{ROR}_{\mathrm{t}}{ }^{+}$expression in $\mathrm{CD}^{+} \mathrm{CD} 4{ }^{+} \mathrm{CD} 25^{+} \mathrm{CD} 127^{\text {lo }} \mathrm{Foxp}^{+}$cells between subjects with acute high-grade maternal inflammation and those without any inflammation.

In addition, we found significantly increased $\mathrm{ROR} \gamma \mathrm{t}^{+}$ cells within the Foxp $3^{+}$cells $\left(\mathrm{CD}^{+}{ }^{+} \mathrm{CD} 4^{+} \mathrm{Foxp}^{+}{ }^{+} \mathrm{ROR} \gamma \mathrm{t}^{+}\right)$ in individuals with acute high stage fetal and maternal inflammation compared to those without acute or chronic inflammation ( $\beta$ : 35.50, SE: 3.80, $p<0.001$; Table 3). Again, there was no statistically significant difference ( $\beta:-1.80$, SE: $4.28, p=0.68$; Table 3 ) in ROR $\gamma \mathrm{t}$ expression in $\mathrm{CD}^{+} \mathrm{CD} 4{ }^{+} \mathrm{CD} 25^{+} \mathrm{CD} 127^{\text {lo }}$ Foxp $3^{+}$cells in these infants.

When evaluating the small number of subjects with maternal high stage acute inflammation, there was no statistically significant difference in the amount of Foxp3 expression on a per cell basis by mean fluorescence intensity (MFI) between neonates with maternal acute inflammation only compared to neonates without acute or chronic inflammation.

We next sought to determine the relationship between the percentage of $\mathrm{RORyt}^{+}$in $\mathrm{FOXp}^{+}{ }^{+}$compartment and premature rupture of membranes. A logistic regression analysis showed no difference between the percentage of RORyt $^{+}$in Foxp $3^{+}$compartment in those subjects that had premature rupture of membranes and those that did not. 
Table 3 Frequency of RORyt ${ }^{+}$cells in cord blood, organized by site of maternal and/or fetal inflammation and cell type

\begin{tabular}{|c|c|c|}
\hline Cell type & $\begin{array}{l}\text { Chronic inflammation with no acute inflammation }(n=8 / 15) \\
\beta \pm S E\end{array}$ & p-value \\
\hline $\mathrm{RORyt}^{+}$in $\mathrm{CD}^{+}{ }^{+} \mathrm{CD}^{+}{ }^{+} \mathrm{Foxp}^{+}$ & $14.19 \pm 3.59$ & 0.002 \\
\hline $\mathrm{RORYt}^{+}$in $\mathrm{CD}^{+}{ }^{+} \mathrm{CD} 4^{+} \mathrm{CD} 25^{+} \mathrm{CD} 127^{\text {lo }} \mathrm{Foxp}^{+}$ & $-1.10 \pm 2.04$ & 0.6 \\
\hline Cell type & $\begin{array}{l}\text { Maternal high stage acute inflammation (stage } 2 \text { and } 3 \text { ) } \\
(n=2 / 9) \\
\beta \pm S E\end{array}$ & p-value \\
\hline $\mathrm{RORYt}^{+}$in $\mathrm{CD}^{+} \mathrm{CD}^{+} \mathrm{Foxp}^{+}$ & $4.30 \pm 4.30$ & 0.35 \\
\hline $\mathrm{RORyt}^{+}$in $\mathrm{CD}^{+}{ }^{+} \mathrm{CD} 4^{+} \mathrm{CD} 25^{+} \mathrm{CD} 127^{\mathrm{lo}} \mathrm{Foxp}^{+}$ & $-3.97 \pm 6.09$ & 0.54 \\
\hline Cell type & $\begin{array}{l}\text { Fetal and maternal high stage inflammation (stage } 2 \text { and } 3 \text { ) } \\
(n=2 / 9) \\
\beta \pm S E\end{array}$ & p-value \\
\hline $\mathrm{RORyt}^{+}$in $\mathrm{CD}^{+}{ }^{+} \mathrm{CD}_{4}^{+} \mathrm{Foxp}^{+}$ & $35.50 \pm 3.80$ & $<0.001$ \\
\hline $\mathrm{RORyt}^{+}$in $\mathrm{CD}^{+}{ }^{+} \mathrm{CD} 4^{+} \mathrm{CD} 25^{+} \mathrm{CD} 127^{\mathrm{lo}} \mathrm{Foxp}^{+}$ & $-1.80 \pm 4.28$ & 0.68 \\
\hline
\end{tabular}

Note that there is a significant difference in RORyt ${ }^{+}$cells in activated T cells compared in individuals with chronic inflammation with no acute inflammation compared to those with neither acute or chronic inflammation $(p=0.002)$. Also note the increase in RORyt ${ }^{+}$cells in activated T cells in subjects with maternal and fetal high stage inflammation $(p<0.001)$, but not in subjects with maternal high stage inflammation alone

\section{Stillbirth cohort}

Fetal splenic tissue showed significantly decreased Foxp3 staining ( $\beta$ : $-0.11, \mathrm{SD}: 0.04, p=0.01$; Table 4 ) in subjects with acute chorioamnionitis compared to controls. Lung and thymic tissue showed no differences in Foxp3 staining between subjects and controls. Importantly, we found significantly increased CD3 staining in lung tissue in deceased subjects exposed to acute chorioamnionitis $(\beta: 0.38$, SD: 0.17 , $p=0.05$; Table 4) compared with controls. We found no differences in thymic or splenic CD3 staining in subjects with acute chorioamnionitis. We also found no differences in any tissue's CD20 staining individuals with or without chorioamnionitis. Figures 2 and 3 show the representative staining for Foxp3 and CD3 in subjects with and without chorioamnionitis.

Lastly, a secondary non-parametric analysis, to account for the data non-normality using the median percent area stained from each subject, yielded the same findings as the linear mixed model analysis.

\section{Discussion}

This investigation provides an initial immunologic characterization of human cord blood and tissue responses to acute high stage placental inflammation and chronic placental inflammation. We found a significantly increased frequency of cord blood RORyt ${ }^{+} \mathrm{Foxp}^{+}$cells in individuals with both chronic placental inflammation and high stage acute fetal inflammatory response in the placenta. Moreover, we found that fetal tissue responses to histologic acute chorioamnionitis revealed a decreased percentage of splenic Foxp $3^{+}$cells in the stillbirth subjects. We also found an increase in percentage lung
$\mathrm{CD}^{+}$cells in stillbirth subjects that had chorioamnionitis compared with controls. We believe that these findings suggest that decreased Foxp $3^{+}$cells in the spleen in acute chorioamnionitis may be associated with a decreased T-regulatory component and concomitant upregulation of activated T-cells in the lung. It is possible, but not yet proven, that these changes may contribute to a proinflammatory environment in the lung and confer this increased asthma risk seen in these patients.

Animal models have demonstrated plasticity between $\mathrm{T}_{\text {reg }}$ or $\mathrm{T}_{\mathrm{H}} 17$ cells after exposure to specific cytokines $[20,21]$. Foxp3 can be transiently upregulated with inflammation in the human. Thus, it is possible that the Foxp $3^{+} \mathrm{ROR} \mathrm{t}^{+}$cells represent either activated $\mathrm{T}_{\mathrm{H}} 17$ cells or regulatory $\mathrm{T}$ cells that are now expressing a pro-inflammatory phenotype. Additionally, "regulatory Th-17 cells" that express both Foxp3 and RORyt have been described that have immunosuppressive properties in the gut. These cells likely promoting tolerance to the microbiota. It is likely that the context of Foxp $3^{+} \mathrm{ROR} \gamma \mathrm{t}^{+}$ cells determine if they are pathogenic (for example in setting of inflammation) or tolerogenic (microbiota) [15]. Given this duality of function, it is not clear if the cells we describe are truly pathogenic vs tolerogenic; however, we suspect they are pro-inflammatory given the setting of inflammation in chorioamnionitis and that they were not isolated from the gut.

Although Foxp3 expression can block RORyt activity on target genes during $\mathrm{T}_{\mathrm{H}} 17$ cell differentiation RORytdependent IL-17 expression can still occur in the presence of Foxp3 with IL-6 exposure [21, 22]. Because the cytokine profile in acute chorioamnionitis includes 


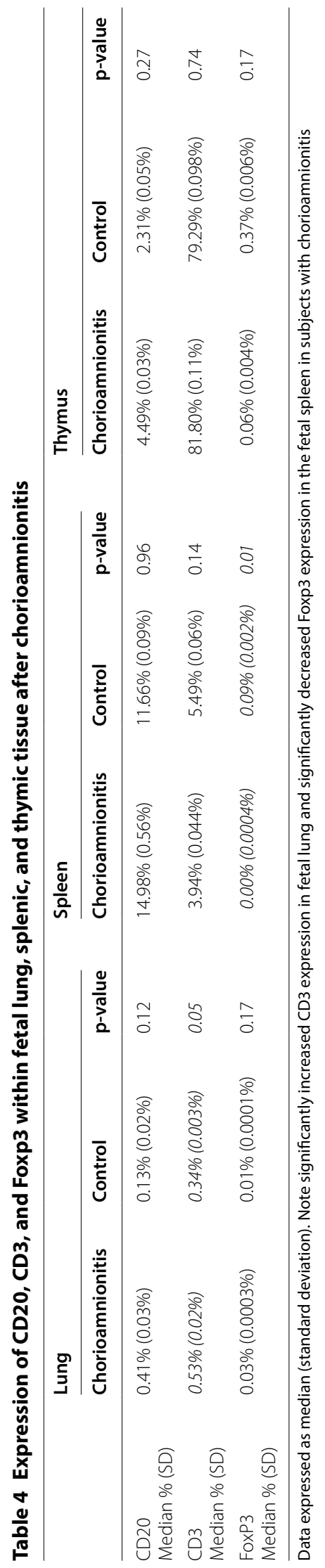



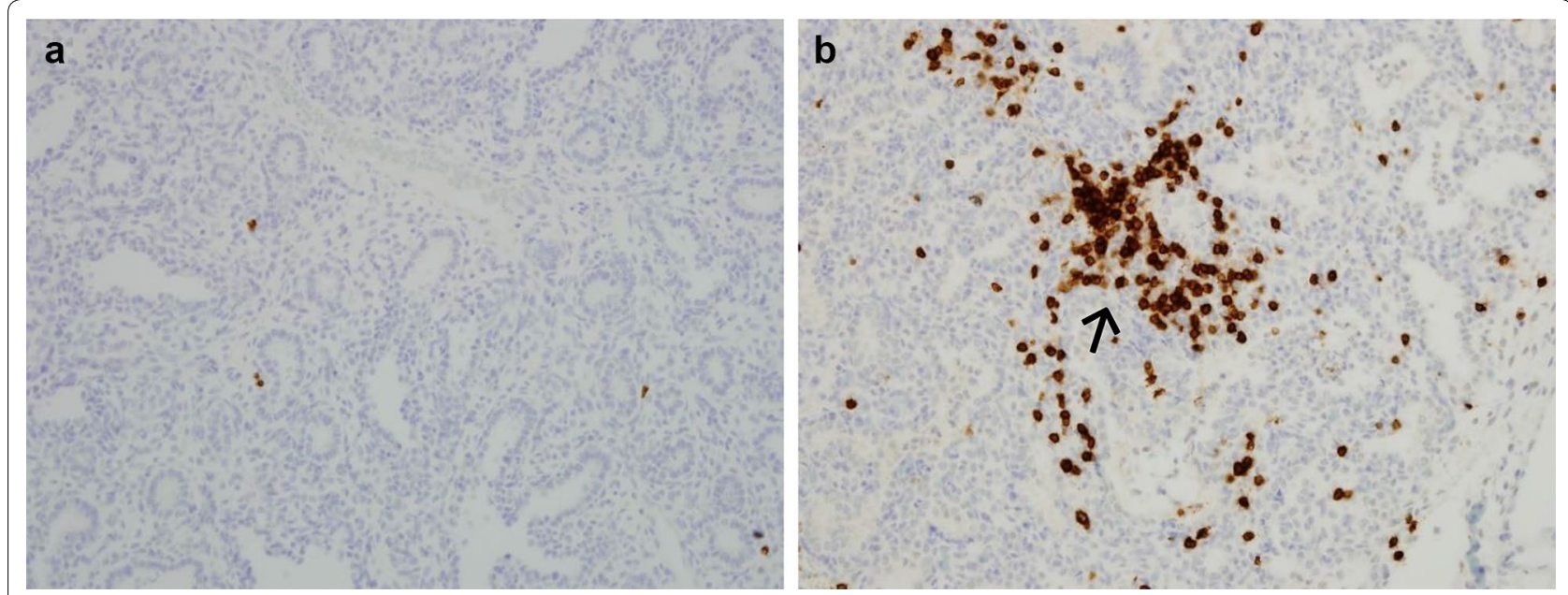

Fig. 2 Stained tissue samples in individuals with and without chorioamnionitis. a CD3 staining of lung in subject without chorioamnionitis. b CD3 staining of lung in subject with chorioamnionitis. Note the increased CD3 stained lung tissue (indicated by the $\rightarrow$ ) in the subject with chorioamnionitis (b) compared to the subject without the disease (a)

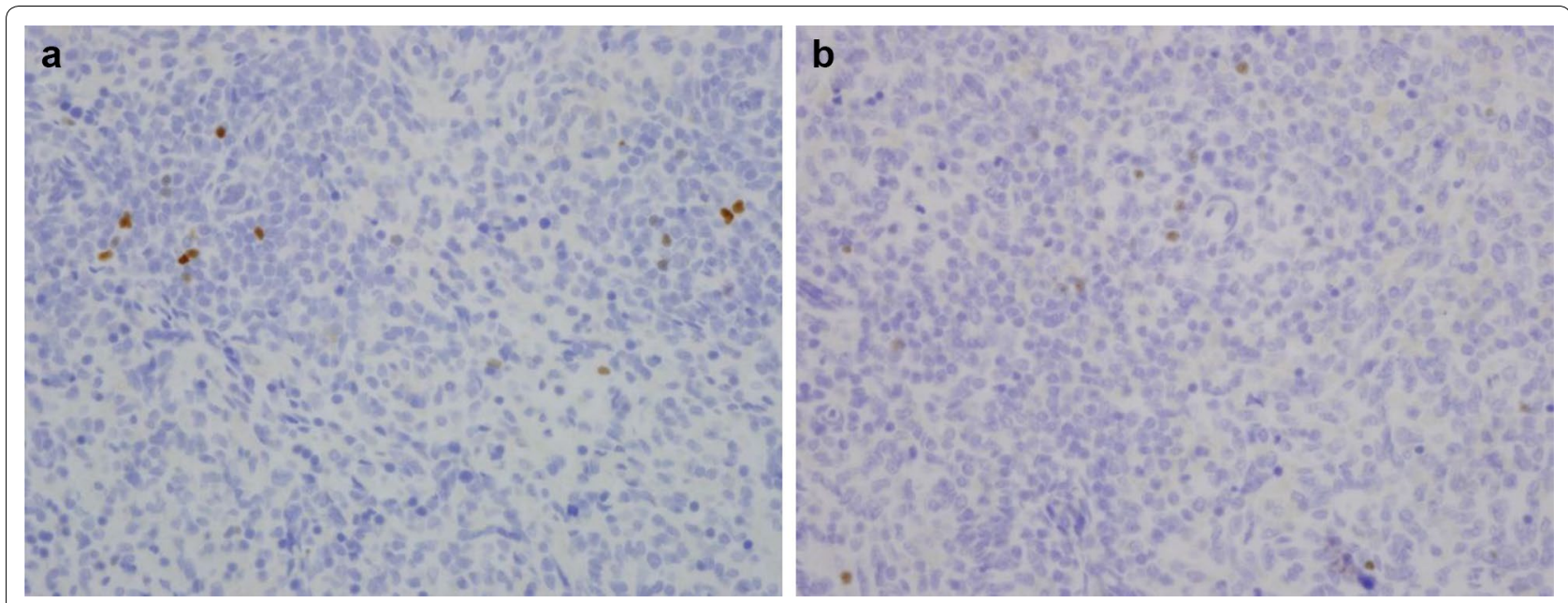

Fig. 3 Stained spleen tissue samples in individuals with and without chorioamnionitis. a Foxp3 staining of spleen in subject without chorioamnionitis. b Foxp3 staining of spleen in subject with chorioamnionitis. Note there is no histologic difference in splenic FoxP3 stained tissue between the two subjects

significant increases in IL-6, we speculate that these increases in IL-6 contribute to elevation of RORyt ${ }^{+}$ cells seen in our analysis. Furthermore, work from non-human primate models have shown increased $\mathrm{T}_{\mathrm{H}} 17$ cells in a chorioamnionitis fetal inflammatory response [23]. The exposed primates also showed decreased thymic and splenic $\mathrm{T}_{\text {reg }}$ frequency [23]. These findings, similar to our own, suggest a transition from regulatory to inflammatory phenotype in response to chorioamnionitis.
The lack of difference in T-cell numbers in samples with maternal acute inflammatory response alone in the placenta compared to samples with controls might be accounted for by the small numbers of subjects in the sample or the severity of inflammation in the fetus. Maternal and fetal acute inflammatory responses in the placenta may promote more widespread/systemic inflammation within the fetus, leading to the increased $\mathrm{T}_{\mathrm{H}} 17$ cells. It is unknown whether increased ROR $\gamma \mathrm{t}$ expression may then prime individuals to have a persistent pro-inflammatory state, and whether this 
pathway explains the increased risk of subsequent asthma in childhood [1, 2]. Notably, the subjects with high stage fetal acute inflammation also had chronic placental inflammation, making it not possible to control for the effects of chronic placental inflammation due to collinearity. However, we note the effects of fetal inflammation are much greater than those seen in chronic inflammation by itself. When we restricted the analysis to those who had chronic inflammation but no chorioamnionitis, these subjects showed similar responses, though smaller in magnitude, to those with fetal inflammation. This suggests that chronic low-grade inflammation may result in similar though less pronounced immune deviation. This distinction is important to make because acute and chronic chorioamnionitis represent different pathological entities with acute chorioamnionitis manifested by neutrophilic inflammation and typically associated with acute infection [24, 25]. Chronic chorioamnionitis is a lymphocytic infiltrate which includes villitis of unknown etiology and may have some associated inflammatory or alloimmune factors [26]. Animal models to date have been carried out with LPS injection resulting in massive and acute increases in IL-1b and IL-6 $[17,18]$. It was not clear that chronic inflammatory lymphocytic changes would have similar levels of inflammatory cytokine expression. As such, it was important to determine if the systemic and organ responses are the same in acute and chronic inflammation.

In addition to animal models, Jackson et al. investigated the association between chorioamnionitis exposure and the cellular profile from cord blood and weekly for the first 4 weeks of life in extremely preterm infants ( $\leq 28$ weeks gestation) [27]. They analyzed mRNA expression of RORC, TBET, GATA3, and FOXP3 in unstimulated cells and several inflammatory cytokines [27]. They found that at 1 week of life infants, with funisitis exposure and not chorioamnionitis exposure had increased RORC expression and RORC/FOXP3 ratio, which continued over the first 4 postnatal weeks [27]. Our current study adds to these findings by suggesting differential cellular RORyt expression in infants exposed to chorioamnionitis, suggesting a skewing towards a $\mathrm{T}_{\mathrm{H}} 17$ phenotype after fetal stress. In addition, while Jackson et al. used mRNA analysis, our study investigated cell marker protein expression, which lends additional insight. Furthermore, while Jackson et al. investigated the association between chorioamnionitis/funisitis on preterm infants, our study used term infants [27]. Lastly, our investigation analyzed tissue differences in cell expression in addition to cord blood differences, which has not been previously studied in humans.
We also noted increased percentage of pulmonary $\mathrm{CD}^{+} \mathrm{T}$-cells and decreased splenic Foxp $3^{+} \mathrm{T}$-cells with acute chorioamnionitis. The increase in $\mathrm{CD}^{+}{ }^{+} \mathrm{T}$-cells in the lung and decrease in Foxp $3^{+}$expressing cells in the splenic tissue may indicate localized pulmonary increases in inflammation with decreased regulatory responses systemically. Importantly, this early life inflammatory predisposition in the airway may be integral in increasing the risk for wheezing and asthma seen in these patients. Supporting this notion, animal models have shown an increased splenic $\mathrm{CD}^{+}$cells after exposure to lipopolysaccharide seen in intrauterine inflammation [7]. In our study, we found fewer Foxp3 cells in the spleen in infants with chorioamnionitis. This decrease in Foxp3 cells may be an effect of the proinflammatory local environment. Lastly, it is known that IL-6 and TNF-alpha are increased in chorioamnionitis and these cytokines also result in methylation at the Foxp3 promoter, that then down regulates $\mathrm{T}_{\text {reg }}$ cell development [20, 28-32].

Our study does have several limitations. First, the number of subjects with histology acute chorioamnionitis was small in the live birth cohort. This may bias our findings and limit the generalizability based on the limited sample. A larger sample size would ultimately help with this in future studies in order to determine if similar effects are seen in individuals with chorioamnionitis compared with controls. Secondly, in the stillbirth cohort, we could not evaluate RORyt in tissues. Due to technical issues, this analysis was not performed, which ultimately hinders our findings. If RORyt had been evaluated in tissues, we would be able to better determine if the increased $\mathrm{T}_{\mathrm{H}} 17$ profile seen in the cord blood persisted in fetal tissues. We anticipate investigating for tissue $T_{H} 17$ cells in future studies. Furthermore, we did not evaluate the stillborn infants' cord blood. Investigating cord blood in these infants would have been the best way to evaluate any association between systemic and tissue responses to chorioamnionitis by the neonates. We also anticipate performing these in future studies. Due to findings in animal models, we focused on $\mathrm{T}_{\mathrm{H}} 17$ and $\mathrm{T}_{\text {reg }}$ phenotypes with less investigation of other cell types, which is also a limitation [17-19]. Therefore, we would hope to investigate other cell types in addition to $\mathrm{T}_{\mathrm{H}} 17$ and $\mathrm{T}_{\text {reg }}$ cells in future studies. In addition, further investigation including expression studies may show tissue-specific increases of activated $\mathrm{T}_{\mathrm{H}} 17$ cells. Finally, we believe that future investigation should determine whether the observed RORyt cells are $\alpha \beta$ or $\gamma \delta C D 4^{+}$T-cells.

In summary, the presented data supports that hypothesis that fetal inflammation promotes immune deviation seen in patients with chronic placental inflammation or acute chorioamnionitis with a fetal inflammatory response. This immune deviation may 
ultimately play an early role in predisposition to asthma that we observe in infants who had chorioamnionitis. We view our results as a key step into understanding this link between chorioamnionitis and asthma. We hope that future studies investigate whether elevations in $\mathrm{T}_{\mathrm{H}} 17$ cell frequency persist into childhood, and how these may relate to later asthma phenotypes.

\section{Additional file}

Additional file 1: Figure S1. Venn diagram of the number of patients with each combination of inflammation in the live-birth cohort. Note that there were no subjects with only fetal high stage acute inflammation and no subjects with fetal high stage acute inflammation along with chronic inflammation.

\section{Abbreviations}

IL: interleukin; $T_{H}$ 17: $T$-helper-cell 17; $T_{\text {reg: }}$ regulatory $T$-cell; RORyt: retinoic acidrelated orphan receptor gamma t; $\mathrm{MFI}$ : mean fluorescence intensity; FMO: Fluorescence Minus One; H\&E: hematoxylin and eosin.

\section{Authors' contributions}

AS made substantial contributions to conception, design, analysis or tissue and drafting/approval of the manuscript. MS analyzed data, interpreted data, drafted the manuscript. KYK analyzed data, interpreted data, and contributed to manuscript drafts. KE aided in data acquisition, figure generation, and drafting the manuscript. AY analyzed data, interpreted data, and contributed to manuscript and figure generation. KM aided in data acquisition, tissue and blood acquisition, design of the study, interpretation of results, and drafting of the manuscript. LE aided in tissue analysis, data interpretation, and drafting the manuscript. RK conceptualized the study, aided in data analysis and interpretation, contributed to manuscript drafting. All authors read and approved the final manuscript.

\section{Author details}

${ }^{1}$ Division of Allergy and Immunology, Department of Pediatrics, Northwestern Feinberg School of Medicine, Ann and Robert H. Lurie Children's Hospital of Chicago, 255 E Chicago Ave, Box \#60, Chicago, IL 60611, USA. ${ }^{2}$ Department of Preventive Medicine, Northwestern University Feinberg School of Medicine, Chicago, IL, USA. ${ }^{3}$ Biostatistics Collaboration Center, Northwestern University Feinberg School of Medicine, Chicago, IL, USA. ${ }^{4}$ Division of Neonatology, Ann and Robert H. Lurie Children's Hospital of Chicago, Chicago, IL, USA. ${ }^{5}$ Department of Pathology and Laboratory Medicine, Northshore University Health System, Evanston, IL, USA. ${ }^{6}$ Department of Medicine, Northwestern Feinberg School of Medicine, Chicago, IL, USA.

\section{Acknowledgements}

The investigators would like to acknowledge the help of the Northwestern University Pathology Core Facility and Mrs. Bella Shmaltsuyev for performance of all tissue staining.

\section{Competing interests}

The authors declare that they have no competing interests.

\section{Availability of data and materials}

The datasets used and/or analysed during the current study are available from the corresponding author on reasonable request.

\section{Ethics approval and consent to participate}

The Ann and Robert H Lurie Children's Hospital of Chicago and Northwestern University Feinberg School of Medicine institutional review boards approved this investigation.

\section{Funding}

This study was funded by the Tanaka foundation, AAAAI K to R Bridge Grant award, NIAID K23 Al100995, Miller Family Foundation, Melchiorre Family Foundation.

\section{Publisher's Note}

Springer Nature remains neutral with regard to jurisdictional claims in published maps and institutional affiliations.

Received: 27 March 2018 Accepted: 29 August 2018

Published online: 19 November 2018

\section{References}

1. Kumar R, Yu Y, Story RE, et al. Prematurity, chorioamnionitis, and the development of recurrent wheezing: a prospective birth cohort study. J Allergy Clin Immunol. 2008;121(878):884.e6.

2. Getahun D, Strickland D, Zeiger RS, et al. Effect of chorioamnionitis on early childhood asthma. Arch Pediatr Adolesc Med. 2010;164:187-92.

3. Tita ATN, Andrews WW. Diagnosis and management of clinical chorioamnionitis. Clin Perinatol. 2010:37:339-54

4. Jones $\mathrm{MH}$, Corso AL, Tepper RS, et al. Chorioamnionitis and subsequent lung function in preterm infants. PLoS ONE. 2013;8:e81193.

5. McDowell KM, Jobe AH, Fenchel $M$, et al. Pulmonary morbidity in infancy after exposure to chorioamnionitis in late preterm infants. Ann Am Thorac Soc. 2016;13:867-76.

6. Zhu T, Zhang L, Qu Y, Mu D. Meta-analysis of antenatal infection and risk of asthma and eczema. Medicine. 2016:95:e4671.

7. Rocha G. Chorioamnionitis and lung injury in preterm newborns. Crit Care Res Pract. 2013:2013:890987.

8. Burgner DP, Doherty D, Humphreys J, et al. Maternal chorioamnionitis and postneonatal respiratory tract infection in ex-Preterm infants. J Pediatr. 2017;184(62):67.e2.

9. Curley AE, Sweet DG, Thornton CM, et al. Chorioamnionitis and increased neonatal lung lavage fluid matrix metalloproteinase-9 levels: implications for antenatal origins of chronic lung disease. Am J Obstet Gynecol. 2003;188:871-5.

10. Ivanov II, Atarashi K, Manel N, et al. Induction of intestinal Th17 cells by segmented filamentous bacteria. Cell. 2009;139:485-98.

11. Ren J, Li B. The functional stability of FOXP3 and RORgammat in Treg and Th17 and their therapeutic applications. Adv Protein Chem Struct Biol. 2017;107:155-89.

12. Fontenot JD, Gavin MA, Rudensky AY. Foxp3 programs the development and function of $\mathrm{CD}^{+}{ }^{+} \mathrm{CD} 25^{+}$regulatory T cells. Nat Immunol. 2003:4:330-6.

13. Sakaguchi N, Takahashi T, Hata H, et al. Altered thymic T-cell selection due to a mutation of the ZAP-70 gene causes autoimmune arthritis in mice. Nature. 2003:426:454-60.

14. Bovenschen HJ, van de Kerkhof PC, van Erp PE, Woestenenk R, Joosten I, Koenen $\mathrm{HJ}$. Foxp ${ }^{+}$regulatory $T$ cells of psoriasis patients easily differentiate into IL-17A-producing cells and are found in lesional skin. J Invest Dermatol. 2011:131:1853-60.

15. Eberl G. RORgammat, a multitask nuclear receptor at mucosal surfaces. Mucosal Immunol. 2017:10:27-34

16. Korn T, Bettelli E, Oukka M, Kuchroo VK. IL-17 and Th17 cells. Annu Rev Immunol. 2009:27:485-517.

17. Kallapur SG, Presicce P, Senthamaraikannan P, et al. Intra-amniotic IL-1 $\beta$ induces fetal inflammation in rhesus monkeys and alters the regulatory $T$ cell/IL-17 balance. J Immunol. 2013;191:1102-9.

18. Kuypers E, Willems MGM, Jellema RK, et al. Responses of the spleen to intra-amniotic lipopolysaccharide exposure in fetal sheep. Pediatr Res. 2015;77:29-35.

19. Rosen D, Lee J-H, Cuttitta F, Rafiqi F, Degan S, Sunday ME. Accelerated thymic maturation and autoreactive T cells in bronchopulmonary dysplasia. Am J Respir Crit Care Med. 2006;174:75-83.

20. Yang XO, Nurieva R, Martinez GJ, et al. Molecular antagonism and plasticity of regulatory and inflammatory $T$ cell programs. Immunity. 2008;29:44-56 
21. Zhou L, Lopes JE, Chong MMW, et al. TGF $\beta$-induced Foxp3 inhibits TH17 cell differentiation by antagonizing RORyt function. Nature. 2008;453:236-40.

22. Xu L, Kitani A, Fuss I, Strober W. Cutting edge: regulatory T cells induce $\mathrm{CD}^{+}{ }^{+} \mathrm{CD}_{25}{ }^{-}$Foxp $^{-}$T cells or are self-induced to become Th17 cells in the absence of exogenous TGFß. J Immunol. 2007;178:6725-9.

23. Rueda CM, Presicce P, Jackson CM, et al. Lipopolysaccharide-induced chorioamnionitis promotes IL-1-dependent inflammatory FOXP3 ${ }^{+} \mathrm{CD}^{+}$ T cells in the fetal rhesus macaque. J Immunol. 2016;196:3706-15.

24. Khong TY, Mooney EE, Ariel I, et al. Sampling and definitions of placental lesions: Amsterdam placental workshop group consensus statement. Arch Pathol Lab Med. 2016;140:698-713.

25. Kim CJ, Romero R, Chaemsaithong P, Chaiyasit N, Yoon BH, Kim YM. Acute chorioamnionitis and funisitis: definition, pathologic features, and clinical significance. Am J Obstet Gynecol. 2015;213:S29-52.

26. Labarrere CA, Hardin JW, Haas DM, Kassab GS. Chronic villitis of unknown etiology and massive chronic intervillositis have similar immune cell composition. Placenta. 2015;36:681-6.

27. Jackson CM, Wells CB, Tabangin ME, Meinzen-Derr J, Jobe AH, Chougnet CA. Pro-inflammatory immune responses in leukocytes of premature infants exposed to maternal chorioamnionitis or funisitis. Pediatr Res. 2017;81:384-90.

28. Mestan $\mathrm{K}$, Yu Y, Thorsen P, et al. Cord blood biomarkers of the fetal inflammatory response. J Matern Fetal Neonatal Med. 2009;22:379-87.

29. Weatherstone KB, Rich EA. Tumor necrosis factor/cachectin and interleukin-1 secretion by cord blood monocytes from premature and term neonates. Pediatr Res. 1989;25:342-6.

30. Hillier SL, Witkin SS, Krohn MA, Watts DH, Kiviat NB, Eschenbach DA. The relationship of amniotic fluid cytokines and preterm delivery, amniotic fluid infection, histologic chorioamnionitis, and chorioamnion infection. Obstet Gynecol. 1993;81:941-8.

31. Kashlan F, Smulian J, Shen-Schwarz S, Anwar M, Hiatt M, Hegyi T. Umbilical vein interleukin 6 and tumor necrosis factor alpha plasma concentrations in the very preterm infant. Pediatr Infect Dis J. 2000;19:238-43.

32. Bettelli E, Carrier Y, Gao W, et al. Reciprocal developmental pathways for the generation of pathogenic effector $\mathrm{TH} 17$ and regulatory $\mathrm{T}$ cells. Nature. 2006:441:235-8.
Ready to submit your research? Choose BMC and benefit from:

- fast, convenient online submission

- thorough peer review by experienced researchers in your field

- rapid publication on acceptance

- support for research data, including large and complex data types

- gold Open Access which fosters wider collaboration and increased citations

- maximum visibility for your research: over $100 \mathrm{M}$ website views per year

At BMC, research is always in progress.

Learn more biomedcentral.com/submissions 